\title{
Study on Temperature Field Distribution of Asphalt Overlay on Existing Cement Pavement
}

\author{
Peng Yang ${ }^{1, ~ a, ~ N i n g-x u ~ H a n ~}{ }^{2, b}$, Wu-jian Long ${ }^{2, c}$,Ting-yu Zeng ${ }^{1, d}$,Jia-min Mai ${ }^{1, e}$ \\ ${ }^{1}$ School of Habor Engineering,Guangzhou Maritime University,Guangzhou,510725,China \\ ${ }^{2}$ Guangdong Provincial Key Laboratory of Durability for Marine Civil Engineering, Shenzhen \\ University,Shenzhen 518060, China \\ ayangpeng1209@126.com, ${ }^{b}$ nxhan@163.com, ${ }^{9}$ longwujian@126.com, ${ }^{\mathrm{d}}$ 364031972@qq.com, \\ "731725778@qq.com
}

\begin{abstract}
Keywords: Asphalt overlay on existing cement pavement; three-dimensional finite element model;temperature field distribution;road surface temperature;heat exchange

Abstract. Asphalt overlay on existing cement pavement structure design and typical diseases (such as low temperature cracking and fatigue cracking temperature, temperature type of reflective crack) have a strong relationship with temperature; At the same time, vehicle load and temperature stress also produce different effects on asphalt overlay on existing cement pavement. In this paper, through the establishment of three-dimensional finite element model and field test based on the theoretical analysis method, temperature field distribution and influencing factors of asphalt overlay on existing cement pavement were studied. Results showed that different materials and thickness of asphalt overlay on existing cement pavement had weak influence on road surface temperature. The main factor was heat exchange between road surface and the air (namely, solar radiation and air temperature).
\end{abstract}

\section{Introduction}

The analysis and research of the pavement temperature field in the 1920's. As early as in 1926, in the United States in Arlington area, the temperature of asphalt pavement under the condition of natural condition detection was carried out. In 1957, Barber calculated heat conduction equation of the temperature field of pavement based on the surface of semi-infinite medium, and put forward the calculation formula of different asphalt and the highest temperature in the structure [1]. In recent years, some areas of the cement road is about to reach the design life in China. In order to save investment and energy conservation and emissions reduction, asphalt pavement laid on existing old cement concrete road gradually got a wide range of applications (commonly known as "white and black").Asphalt overlay on existing cement pavement structure design and typical diseases (such as low temperature cracking and fatigue cracking temperature, temperature type of reflective crack) have a strong relationship with temperature; At the same time, vehicle load and temperature stress also produce different effects on asphalt overlay on existing cement pavement. Many countries carried out large amount of experimental research on the asphalt pavement and cement concrete pavement and the road surface temperature conditions. From the existing research results, related research methods can be roughly divided into two kinds, namely, on the basis of a large number of test data using probability statistical method to deal with test data after the empirical formula is put forward, and the prediction method for pavement temperature field (statistical analysis), and the basic theory of heat transfer and meteorology method to determine the temperature field of pavement (theoretical analysis).Based on certain assumptions, the temperature field and temperature stress are studied. There are differences between the true temperature field using simulated operation with finite element program. Therefore, it is necessary to study on temperature field model, to get the more accurate established thermal analysis model and boundary conditions.In this paper, through the establishment of three-dimensional finite element model and field test based on the theoretical analysis method, temperature field distribution and influencing factors of asphalt overlay on existing cement pavement were studied. 


\section{Calculated model for temperature field distribution Heat conduction differential equation}

Pavement layer is multilayer system composed of different materials with different thickness. Due to the different thermodynamic parameters of each layer material, heat conduction equation for each layer need to be set up respectively[2], the first layer and inter-layer contact condition for heat conduction equations can be calculated as formula below:

$$
\begin{aligned}
& k_{i} \frac{\partial^{2} T_{i}(z, t)}{\partial z^{2}}=\rho c \frac{\partial T_{i}(z, t)}{\partial t} \\
& T_{i}(z, t)=T_{i+1}(z, t) \\
& k_{i} \frac{\partial T_{i}(z, t)}{\partial z}=k_{i+1} \frac{\partial T_{i+1}(z, t)}{\partial z}
\end{aligned}
$$

Where, $k_{i}$ is thermal conductivity of materials in $i$ layer $\left(\mathrm{W} \cdot(\mathrm{m} \cdot \mathrm{K})^{-1}\right) ; T_{i}$ is the temperature of materials in $i$ layer $\left({ }^{\circ} \mathrm{C}\right) ; \quad \rho$ is the density of materials $\left(\mathrm{kg} \cdot \mathrm{m}^{-3}\right) ; t$ is the time $(\mathrm{s}) ; z$ is the $\operatorname{depth}(\mathrm{m}) ; c$ is the specific heat $\left(\mathrm{J} \cdot(\mathrm{kg} \cdot \mathrm{K})^{-1}\right)$.

\section{Solar radiation}

The diurnal variation of the solar radiation process $(q(t)$ can use the following function to approximate[3]:

$$
q_{s}=\left\{\begin{array}{cl}
0 & 0 \leq t \mathrm{p} 12-\frac{c}{2} \\
q_{0} \cos m \omega(t-12) & 12-\frac{c}{2} \leq t \leq 12+\frac{c}{2} \\
0 & 12+\frac{c}{2} \mathrm{p} t \leq 24
\end{array}\right.
$$

Where, $q_{0}$ is for maximum radiation( noon), $q_{0}=0.131 \mathrm{mQ}, \quad m=12 / \mathrm{c} ; \quad Q$ the daily total solar $\operatorname{radiation}\left(\mathrm{J} / \mathrm{m}^{2}\right) ; c$ is the real effective sunshine time(h); $\omega$ is angular frequency $(\omega=2 \pi / 24, \mathrm{rad})$.

\section{Temperature and current flow heat exchanger}

Due to the influence of solar radiation, air temperature shows the characteristics of periodic changes [4]. Considering the daily minimum temperature usually appear in the dawn(before and after about $4 \sim 6$ in the morning), and the highest temperature appears mostly in the largest solar radiation in about $2 \mathrm{~h}$ (around $14 \mathrm{PM}$ ), so it is less than $10 \mathrm{~h}$ (from the lowest to the highest temperatures), while it is more than $14 \mathrm{~h}$ from highest to lowest temperature. Single sine function can't simulate the actual process of variable temperature, so the two sine function of linear combination equation(5) can simulate the temperature daily variation process, and its result coincides well with the actual situation.

$$
T_{a}=\bar{T}_{a}+T_{m}\left[0.96 \sin \omega\left(t-t_{0}\right)+0.14 \sin 2 \omega\left(t-t_{0}\right)\right]
$$

Where, $\overline{T_{a}}$ is the average daily temperature $\left({ }^{\circ} \mathrm{C}\right), \overline{T_{a}}=\left(T_{a}^{\max }+T_{a}^{\min }\right) / 2 ; T_{m}$ the daily temperature variation $\left({ }^{\circ} \mathrm{C}\right), T_{m}=\left(T_{a}^{\max }-T_{a}^{\min }\right) / 2 ; t_{0}$ is the initial phase, the highest temperature lag time difference in the intensity of the largest solar radiation is 7 , generally a time for $2 \mathrm{~h}$, therefore, can be equal to 9 .The road 
surface heat transfer coefficient $\left(h_{c}\right)$ was mainly affected by wind speed and atmosphere $\left(v_{\omega}\right)$, the linear relationship between them can be calculated by:

$h_{c}=3.7 v_{\omega}+9.4$

Where, $h_{c}$ is the heat transfer coefficient $\left(\mathrm{W} /\left(\mathrm{m}^{2} \cdot{ }^{\circ} \mathrm{C}\right)\right) ; v_{\omega}$ is the daily average wind $\operatorname{speed}(\mathrm{m} / \mathrm{s})$.

\section{Effective radiation of the pavement}

The size of effective radiation of the pavement is mainly decided by the ground temperature, air temperature, cloud cover, air humidity and transparency, and many other factors. In previous studies, the temperature was corrected mostly through proper road surface exothermic coefficient change, or heat effect of effective radiation was calculated by the sun radiation amplitude reduction approximate calculation method [5]. The calculation (7) can be used to realize the ground under the type effective boundary conditions:

$$
q_{F}=\varepsilon \sigma\left[\left(\left.T_{1}\right|_{z=0}-T_{Z}\right)^{4}-\left(T_{a}-T_{Z}\right)^{4}\right]
$$

Where, $q_{F}$ is ground effective solar radiation $\left(\mathrm{W} /\left(\mathrm{m}^{2} \cdot{ }^{\circ} \mathrm{C}\right) ; \varepsilon\right.$ is the road surface emissivity; $\sigma$ is Stephen Boltzmann constant $\left(2.041092 \times 10^{-4} /\left(\mathrm{J} / \mathrm{h} \cdot \mathrm{m}^{2} \cdot \mathrm{K}^{4}\right) ;\left.T_{1}\right|_{Z=0}\right.$ pavement temperature $\left({ }^{\circ} \mathrm{C}\right) ; T_{a}$ is atmospheric temperature $\left({ }^{\circ} \mathrm{C}\right) ; T_{Z}$ is absolutely zero temperature (usually be equal to- $273{ }^{\circ} \mathrm{C}$ )

\section{Finite element model of the temperature field}

(1) The basic assumptions model

Make the following three basic assumptions: Each layer material of the pavement is completely uniform, isotropy, and neither layer thermal characteristic parameters changing with temperature, nor the influence of the change over time; the temperature changing is only related to the thickness, (one dimensional distribution); The road surfaces interface between the layers are always in a state of completely continuous and continuous heat transfer..

(2)Boundary conditions of the model

Due to the pavement structure hypothesis of horizontal temperature gradient is zero, so the lateral boundary conditions can not be considered, so the pavement surface is the main boundary conditions and infinite depths are secondary boundary.Boundary conditions of pavement surface mainly include three kinds: solar radiation, air convective heat and radiation heat transfer and can be calculated by: $\mathrm{q}=\mathrm{q}_{\mathrm{s}}+\mathrm{q}_{\mathrm{h}}+\mathrm{q}_{\mathrm{ap}}$

Where, $q$ is the road surface heat flow density; $q_{s}$ is pavement absorption of solar radiation intensity; $\mathrm{q}_{\mathrm{h}}$ is air and road table of convective heat transfer; $\mathrm{q}_{\mathrm{ap}}$ is radiation heat transfer.

\section{(3)The basic parameters of the model}

Total solar radiation, extreme low and high temperature, sunshine duration, average wind speed according to the four seasons are roughly considered according to Table 1 . Numerical reference are from southern humid area in the four seasons climate of representatives in January, April, July and October data(representing the area four seasons, spring, summer, autumn, winter). Thermal characteristics of the structural layer value are showed in Table 2.

Table1. The boundary conditions of temperature field analysis

\begin{tabular}{|c|c|c|c|c|c|}
\hline Month & $\begin{array}{c}\text { Total solar } \\
\text { radiation } / 10^{6} \mathrm{~J} / \mathrm{m}^{2}\end{array}$ & $\begin{array}{l}\text { Sunshine } \\
\text { duration/ } \\
\mathrm{h}\end{array}$ & $\begin{array}{l}\text { Extreme } \\
\text { high } \\
\text { temperature } \\
\quad /{ }^{\circ} \mathrm{C}\end{array}$ & \begin{tabular}{l} 
Extreme \\
low \\
temperature \\
\multicolumn{1}{c}{$/{ }^{\circ} \mathrm{C}$}
\end{tabular} & $\begin{array}{l}\text { Average wind } \\
\text { speed } \\
\qquad \mathrm{m} / \mathrm{s}\end{array}$ \\
\hline January & 10.48 & 7.9 & 17 & 8.6 & 1.9 \\
\hline April & 14.17 & 7.2 & 23.8 & 16.2 & 2 \\
\hline July & 25.19 & 11 & 37 & 28.8 & 2.4 \\
\hline October & 14.52 & 9.4 & 27.7 & 18.8 & 2.3 \\
\hline
\end{tabular}


Table 2. Thermal characteristics of the structural layer

\begin{tabular}{|c|c|c|c|c|c|c|}
\hline Structural layer & $\begin{array}{l}\text { Thickne } \\
\text { ss/cm }\end{array}$ & $\mathrm{k} / \mathrm{J} / \mathrm{m} \cdot \mathrm{h} \cdot{ }^{\circ} \mathrm{C}$ & $\begin{array}{l}\mathrm{c} / \mathrm{J} / \mathrm{kg} \cdot{ }^{\circ} \\
\mathrm{C}\end{array}$ & $\alpha_{\mathrm{s}}$ & $\varepsilon_{\mathrm{p}}$ & $\begin{array}{l}\text { Density } / \mathrm{k} \\
\mathrm{g} / \mathrm{m}^{3}\end{array}$ \\
\hline Asphalt overlay & 4-10 & $4500-\mathbf{4 6 8 0}$ & 925 & $\begin{array}{l}0.63-0.9 \\
0\end{array}$ & $\begin{array}{l}0.82-0.9 \\
\mathbf{3}\end{array}$ & 2300 \\
\hline $\begin{array}{l}\text { Cement } \\
\text { pavement }\end{array}$ & 22-26 & 5400-6480 & 730 & $\begin{array}{l}\text { 0.60- } 0.7 \\
7\end{array}$ & $\begin{array}{l}0.80-\mathbf{0 . 8} \\
\mathbf{8}\end{array}$ & 2400 \\
\hline $\begin{array}{l}\text { Cement } \\
\text { stabilized base }\end{array}$ & 40 & 3420 & 817 & & & 2077 \\
\hline $\begin{array}{l}\text { Calcareous soil } \\
\text { subbase }\end{array}$ & 80 & 4187 & 879 & & & 1757 \\
\hline Soil base & - & 5616 & 1040 & & & 1800 \\
\hline
\end{tabular}

\section{Temperature field distribution of asphalt overlay on existing cement pavement}

The sun is the only source of heat of the earth, the influence of the change of solar radiation on pavement temperature is very large. In one day, solar radiation changes in the form of a half sine wave, the maximum generally appears at about 12 noon.After sunset to sunrise before, strength value is 0 . The sun total radiation nearly twice as high as the maximum in summer than in winter; From summer to winter, total radiation time also gradually delayed in the morning, and the sunset in total radiation to zero value ahead of time, this is because the summer sunshine during the day time is relatively caused by the long winter. Environmental factors such as the temperature changes with the day time and every season time.

\section{Temperature field distribution}

In this study, the depth of asphalt overlay pavement is taken as $10 \mathrm{~cm}$, the depth of the existing cement pavement is taken as $22 \mathrm{~cm}$. In order to ensure the accuracy of finite element calculation, four consecutive days are taken.Figure 1 shows the temperatures of asphalt overlay surface change with time. During 96 hours, the change of the temperature is similar,but the temperature in July is highest and January is lowest.

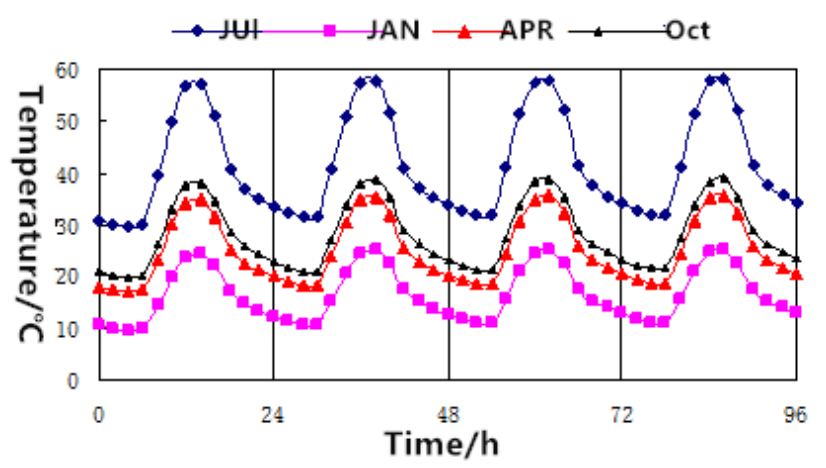

Figure 1. The change of surface temperature(four seasons, 96 hours)

\section{Atmospheric temperature (AT) and asphalt overlay temperature (OT)}

From figure 2, asphalt overlay temperatures (the environment temperature ) of the four seasons change with the time. But between the environment temperature and the asphalt overlay temperature, there is obvious deviation, this is largely due to the effect of solar radiation. It is clear that deviation is significantly in the periods of strong solar radiation. When there is no solar radiation, the asphalt overlay temperature is higher than the environment temperature because of heat dissipation. In July, 
deviation between AT and OT is largest (reach to $20.96^{\circ} \mathrm{C}$ ). In January, the deviation between AT and $\mathrm{OT}$ is smallest (reach to $8.15^{\circ} \mathrm{C}$ ).

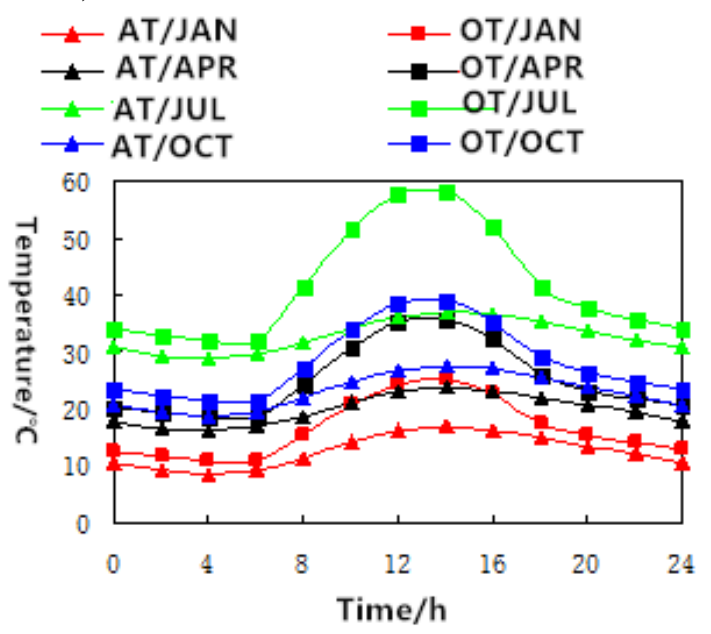

Figure 2. Atmospheric temperature (AT) and asphalt overlay temperature (OT)

\section{Temperature field distribution along the depth}

Figure 3 and 4 analyzed temperature changes along the different thickness. With the increase of the depth of pavement, pavement structure temperature decreased gradually, and the amplitude of change also decreased with nonlinear style. When the depth reached a certain value, the temperature change was very small (especially in the old plate at the bottom of the temperature change). In January, by the calculation the thickness of $72 \mathrm{~cm}$, the difference between maximum and minimum temperature was $0.4765^{\circ} \mathrm{C}$; When thickness is $102 \mathrm{~cm}$, the difference between maximum and minimum temperature was only $0.2986{ }^{\circ} \mathrm{C}$. When depth reaches a certain limit, (because of the temperature of pavement structure by solar radiation, temperature and so on), the temperature field distribution difference is very big.In addition, all the temperature change trend has two cases. The surface temperature in 8:00AM to 4:00PM is larger than following structure layer temperature.And other time, the situation is the opposite, it is related to solar radiation.

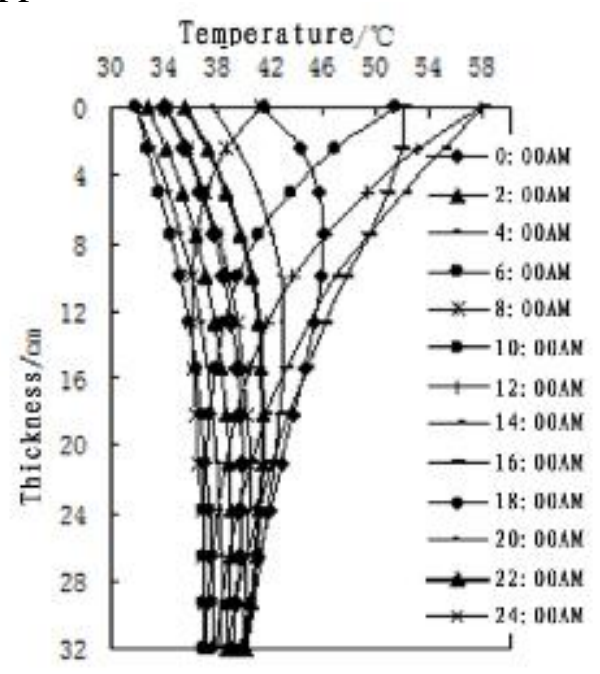

Figure 3. Temperature along the depth changes at different time(In January) 


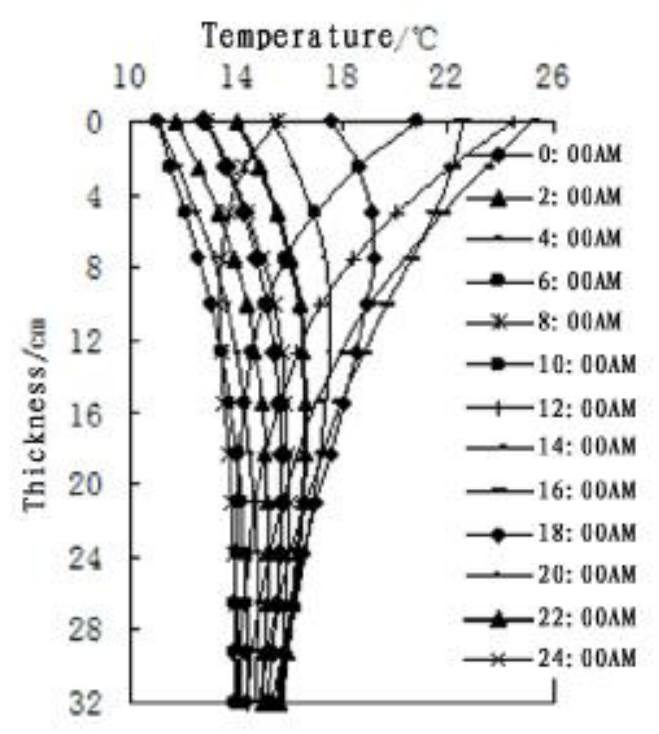

Figure 4. Temperature along the depth changes at different time(In July)

During the day, in 8:00AM to 4:00PM solar radiation is big, so the road surface temperature is larger than other structure layer; In other time, the solar radiation is very small or even zero, road table bottom temperature is lower than the road structure layer, so the corresponding temperature is large than surface temperature.From figure 3and 4, temperature distribution is roughly same,but the temperature fluctuation values vary widely. The temperature in summer is significantly different from in winter .

\section{Temperature field distribution over time}

From Figure 5, minimum temperature of asphalt overlay on existing cement pavement appears at about 5:30 AM(the temperature is $11.031^{\circ} \mathrm{C}$ ); And the highest temperature between two 1:00PM to 2:00PM is up to $25.2996^{\circ} \mathrm{C}$ in the afternoon. With the increase of depth, the temperature of the phase lag changes, the temperature of the existing cement pavement appears at about 6:30AM, the highest temperature appears at about 4:00 PM and is up to $19.663^{\circ} \mathrm{C}$. The lag of highest temperature is due to the transition from the surface to the internal structure, and there is a certain relationship and material thermal conductivity. And the lag of the lowest temperature is because of pavement structure layer of heat dissipation(the underlying heat slower than the surface). As can be seen from the curves of daily temperature because of the sun radiation, the surface temperature of heating and cooling process of time is not equal, heating process is about 8 to 10 hours, and cooling process about 14 to 16 hours.

Temperature field changes with time in the four seasons have the certain regularity. From Figure 6 , in July, each layer temperature is relatively high, and in January, each layer temperature is relatively low. In asphalt overlay, in January, the highest temperature is $25.299{ }^{\circ} \mathrm{C}$, the temperature is the highest temperature of $57.957^{\circ} \mathrm{C}$ in July. The temperature of the environment and the climate is the corresponding, the pavement temperature is affected by temperature significantly. The temperature of asphalt overlay on existing cement pavement in the four seasons follows the laws: July >October >April > January. The thickness of asphalt overlay has a little influence on the maximum temperature, but the highest temperature of Existing Cement Pavement is affected significantly, and has a great influence on the temperature lag amplitude. So, increasing asphalt overlay thickness will not produce obvious effect on prevention and control of road table temperature shrinkage cracking, but in the prevention and control of temperature shrinkage type of reflective crack it has obvious effects. But the Existing Cement Pavement thickness change has not obvious effect accordingly.Cement Pavement thickness change has not obvious effect accordingly. 


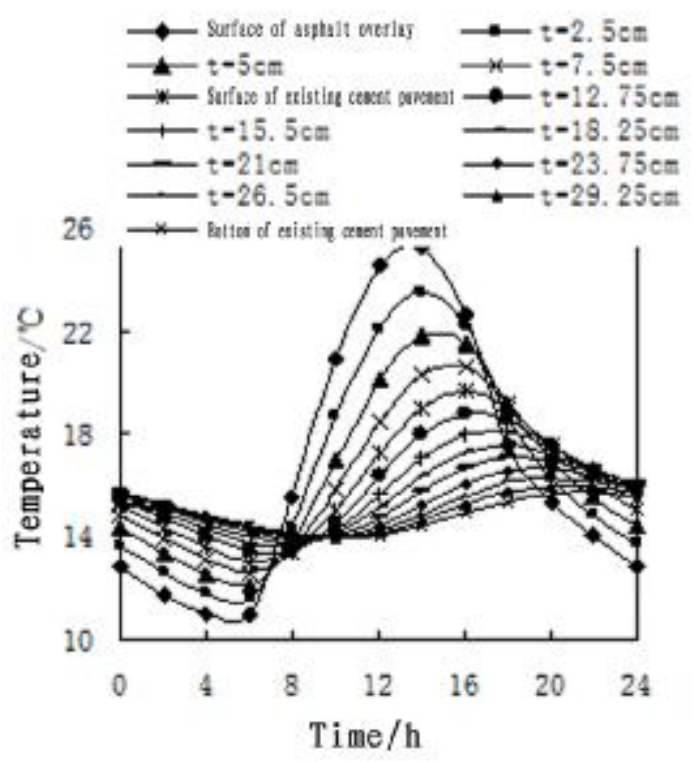

Figure 5.Temperature along the thickness changes in January

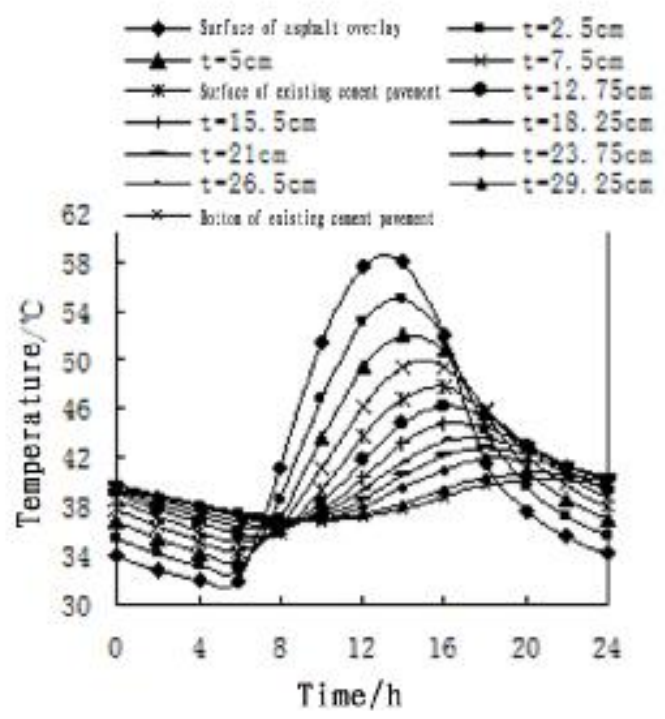

Figure 6.Temperature along the thickness changes in July

\section{Conclusions}

The temperatures of asphalt overlay surface change with time,during 96 hours, the change of the temperature is similar,but the temperature in July is highest and January is lowest..It is clear that deviation is significantly in the periods of strong solar radiation. In July, deviation between AT and OT is largest (reach to $20.96^{\circ} \mathrm{C}$ ). In January, the deviation between AT and OT is smallest (reach to $8.15^{\circ} \mathrm{C}$ ). Temperature distribution is roughly same, but the temperature fluctuation values vary widely. The temperature in summer is significantly different from in winter.

\section{Acknowledgements}

The authors acknowledge financial support by Guangdong Provincial Key Laboratory of Durability for Marine Civil Engineering(Project number:GDDCE15-06), Guangdong annual college students in science and technology innovation and cultivation of special funds project/Climbing plan special funds (pdjh2017b0386), China college students innovation and entrepreneurship training programs (D420821, E321020). 


\section{References}

[1] MA Qing-lei,YANG Bin,et al. (2005). Thermal stress of asphalt overlay on cement concrete pavement[J].Journal of Shan-dong University(Engineering science),2005,35(2),pp:103-106.

[2] SHEN Ai-qin,JIA Yu(2008). Finite element analysis of temperature stress in Polymer Modified Cement Concrete and Porland Cement Concrete(PMCC-PCC) composite pavement[J].Journal of Chang'an University(Naturanl Science Edition). 2008,28(03),pp:21-24.

[3] DIYYAR B(2002).Three dimensional finite element analysis to evaluate reflective cracking potential in asphalt concrete overlays[D].University of Illinois,2002,pp:54-72.

[4] TAN Zhi-ming, YAO Zu-kang,et al. (2003). Thermal stress analysis of two-layered concrete slabs[J].China Journal of Highway and Transport,2003, 16(2),pp:10-12.

[5] KANG Hai-gui,ZHENG Yuan-xun,et al. (2007).Regression analysis of actual measurement of temperature field distribution rules of asphalt pavement [J].China Journal of Highway and Transport, 2007,20 (6),pp:13-18. 